\title{
The rapidly evolving role \& implications for cross-industry convergence in the U.S. healthcare system
}

\author{
Alia Manetta \\ Accenture Strategy \& Management Consulting, San Francisco, CA, USA \\ Correspondence to: Alia Manetta. Accenture Strategy \& Management Consulting, San Francisco, CA, USA. Email: alia.c.manetta@accenture.com.
}

Received: 24 July 2020; Accepted: 11 January 2021; Published: 30 April 2021.

doi: $10.21037 / \mathrm{ht}-20-26$

View this article at: http://dx.doi.org/10.21037/ht-20-26

\section{Introduction}

From the 1700 s to the early 2000 s, healthcare services required patients to make a journey to healthcare offices, centers, and hospitals. In these environments, humans were described as "patients". Yet, at some point in the recent decade, these patients became termed as "consumers"a term which implies competitive markets, freedom of choice, price transparency, and free-market capitalism. As John Donvan eloquently questioned in a 2019 IQ2 debate: "If humans are consumers of healthcare, then who decides how to best provide for them?" (1). Some may say the U.S. government or current healthcare authorities. Adversaries would argue for large technology companies, retail alliances, and other cross-industry players shifting industry boundaries. Decision-makers and executives alike have struggled to identify and build relevant approaches, capabilities, and leadership needed to sustain consumer interest, and overcome competition in our new era of digital innovation and healthcare convergence.

This commentary identifies four strategic imperatives that play determining factors in how incumbents and new entrants can advance in the rapidly evolving healthcare marketplace. Each section analyzes ongoing shifts across the healthcare continuum, recommends digital strategies that enable organizations to overcome industry challenges, and invites readers to re-examine the evolving healthcare landscape with a newer awareness. A firm understanding of these four imperatives serves as a substantive tool for optimizing future business strategy, for enabling effective strategic planning, and for unlocking new possibilities for improved healthcare delivery.

\section{The next frontier of patient-driven innovation}

In the coming year, we're going to wake up to a new era that will be dominated by an increasing number of industries that will converge under newer, broader, and more dynamic alignments. The digital revolution has accelerated in the past decade with enormous enhancements to advanced analytics, ubiquity of mobile interfaces, rapidly evolving intelligent automation, and the ever-growing potential of machine learning and artificial intelligence (AI).

Prior to the digital revolution, traditional consumer experiences were dominated by standardized mass market services and asynchronous communication methods. Nowadays, consumer expectations and experiences have shifted considerably. New digital solutions across industries have driven consumers to expect personalized approaches, multi-channel experiences, synchronous communication methods, and immediate engagement. Each year, consumer preferences are evolving at an even faster pace, as they are informed by previous experiences agnostic to industry sectors. The next generation of digital-first consumers are demanding high standards when seeking and engaging healthcare support. This will require traditional healthcare organizations to pivot significantly, in order to meet consumer's evolving values, expectations, and lifestyle preferences.

New competitive entrants from non-traditional sectors (such as consumer goods, retail, technology, etc.) are attracted by the scale of this opportunity. A wide range of non-traditional organizations are creating multi-million and multi-billion-dollar investments across the healthcare sector in order to pioneer a variety of new products and services 
Net Promoter Score (NPS) Benchmarks

Healthcare vs. Consumer-Centric Companies

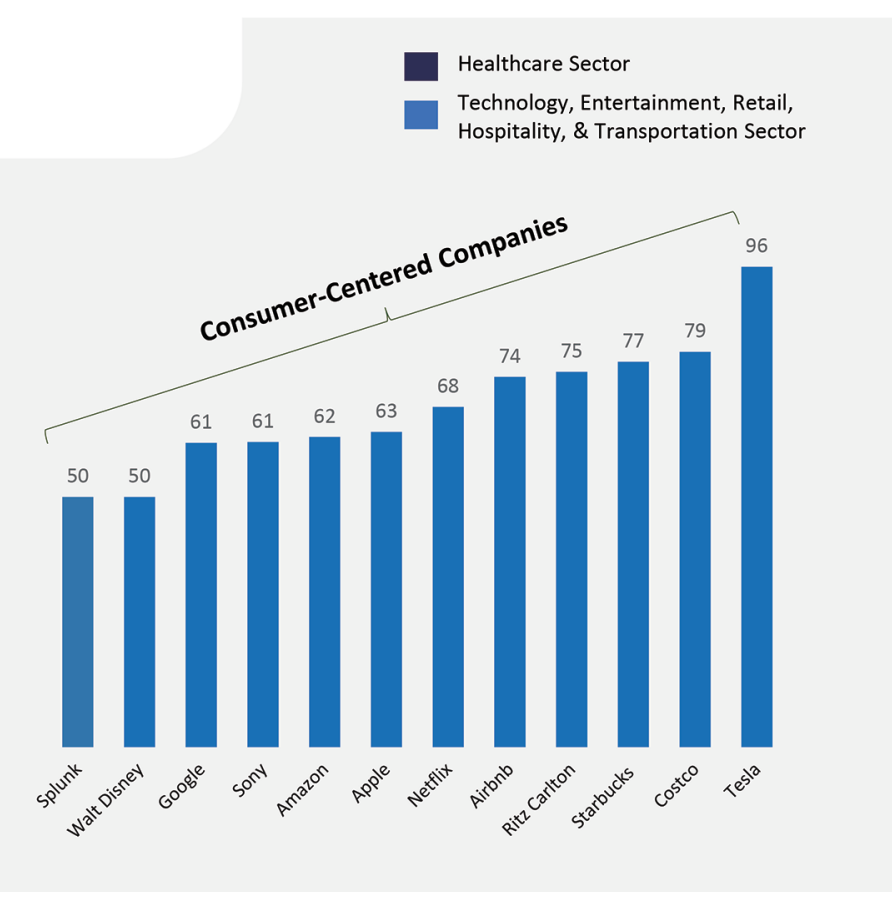

Figure 1 Patient-Centered Care? Think again. This table presents the Net Promoter Score (NPS) of key healthcare organizations compared to other industry sectors. The NPS score, a business index and leading indicator of consumer satisfaction and loyalty, was compared between a broad range of consumer-focused companies (technology, consumer goods, hospitality, others) and healthcare incumbents.

that compete with the large healthcare incumbents. The following section details striking differences between these industry players. Understanding the current healthcare climate driving change, and using key trends to predict the future will help players stay abreast of critical industry shifts and prepare as the pace of change continues to accelerate. The following four imperatives explore current macrotrends which highlight how non-traditional players are shifting industry norms. It also details how current players can harness digital strategies, overcome competitive pressures, and drive consumer-centered strategies to better serve their patients.

\section{Patient-centered care? think again}

The evolution and rapid growth of technological innovation makes the consumer healthcare experience and patientcentered care more important now more than ever. Patient-centered care, a critical milestone and mission for many health organizations, is defined as: "providing care that is respectful of and responsive to individual patient preferences, needs and values and ensuring that patient values guide all clinical decisions" (2).

While many large healthcare organizations have patientcentered missions, in actuality, a large majority of these healthcare organizations are laggards in demonstrating lasting patient engagement and consumer loyalty practices relative to other industries. The Net Promoter Score (NPS), a business index and metric used in customer experience programs, serves as an indicator of consumer satisfaction, engagement, and loyalty. Figure 1 compares the NPS score between numerous dominant healthcare players, and several non-healthcare consumer-focused organizations such as technology, consumer goods, hospitality, among others (3-7). Findings suggest that the average NPS score for healthcare was $\sim 2-3 \times$ lower than averages for other industries such as ecommerce, construction, software, and education (8). Thus, consumers of healthcare products and services are less likely to advocate for their providers and insurance, compared to other services from non-healthcare sectors (9).

In an era of constant growth and change, the organizations who can capture consumer satisfaction, engagement, and loyalty will define what it means to be a leading healthcare 
company. Non-healthcare organizations, who present a higher NPS score and a stronger mastery of creating and maintaining consumer loyalty, will play a competitive role against current healthcare players. Traditional healthcare players, who currently present much lower NPS scores, must respond quickly to earn customer loyalty and satisfaction, maintain patient retention metrics, and combat disruption from cross-industry competition.

As healthcare innovation and digital health tools become widespread, patients will increasingly gain ease in switching healthcare providers and finding coverage elsewhere. This will require organizations in the healthcare sector to focus even more strongly on patient loyalty and patient-centered care to maintain patient retention metrics. Research from Bain \& Company, indicated that a $5 \%$ increase in customer loyalty can result in profitability gains by $25 \%$ (10). Achieving increases in loyalty metrics, such as the NPS score, has also correlated to improvements in clinical-related outcomes such as re-admission rates and health care compliance (11). Yet, successful execution of patient-centered delivery requires significant shifts in digital strategy, improved enterprise-wide technological healthcare programs, and long-term strategic initiatives grounded in cross-industry research. To attain this successful growth and change, healthcare incumbents must focus on four imperatives.

\section{Four key imperatives}

\section{Moving from brick-and-mortar to mHealth/connected consumer journey}

Large pharmacy chains and retailers like Walgreens, CVS Health, Rite Aid, Publix, Target, and Walmart are maneuvering away from direct-to-consumer (DTC) health clinics for non-urgent care, and moving towards mobile health (mHealth) platforms and connected health services. For example, in 2019 the pharmacy chain, Walgreens, closed 160 Retail Health Clinics, to re-focus on telehealth partnerships with health systems for chronic care patients and seniors. Walgreens' decision to maneuver away from DTC telehealth clinics for non-urgent care, and instead move towards mHealth and connected health services is not an uncommon strategy.

These large players like Walgreens are not doing it alone. Instead, large retailer and healthcare organizations are teaming up with technology giants to create consumer- centric unified value propositions (12). In 2019, Walgreens announced a strategic partnership with Microsoft "to create a connected health platform that includes telehealth stations, digital health tools and a seamless ecosystem that connects the consumer to providers, payers and others in the healthcare landscape" (13). Together, technology and retail alliances like Walgreens/Microsoft, will reshape the customer experience and redefine innovation at a more rapid pace than previously experienced. Large healthcare players must dramatically enhance their ability to provide user-friendly connected health services. They must also rapidly build critical cross-functional internal capabilities which combine engineering, design, and science in order to set the direction for how their healthcare consumer experiences will evolve in the coming years.

\section{Cross-Industry Convergence and Consolidation}

Industry convergence and consolidation is reshaping the future of healthcare. Many healthcare incumbents lack robust in-house technology capabilities to compete with their agile technology competitors. While it may be enticing for healthcare providers to assume that aggressive M\&A strategies will be the end-all-be-all solution for achieving tremendous success; to-date successful integration and consolidation has proven challenging. Strategic focus on company core competencies, market-entry strategy, and value differentiation will allow successful combinations of new, dynamic alignments and successful outsourcing of non-core activities to high performing partners. Notable examples of non-healthcare organizations accelerating their pursuit of the healthcare market are listed in Figure 2. Their strategic approaches are wide-ranging, including but not limited to: building a niche in the care-delivery-at-adistance market, to selling high-margin healthcare-related hardware, to building AI tools aimed at improving clinical care (9,14-18).

Not every example above portends a radical shift for the healthcare industry. However, a sound market entry and growth strategy by successful non-traditional players will enable new profitable positions in the market. Healthcare companies who do not build and foster longterm relationships with technology players, or who do not establish increased patient loyalty should prepare for their consumers to leave for the competition. If even one of these technology players listed above are successful in their endeavors, it will influence healthcare in an impactful way. 
New Business Models

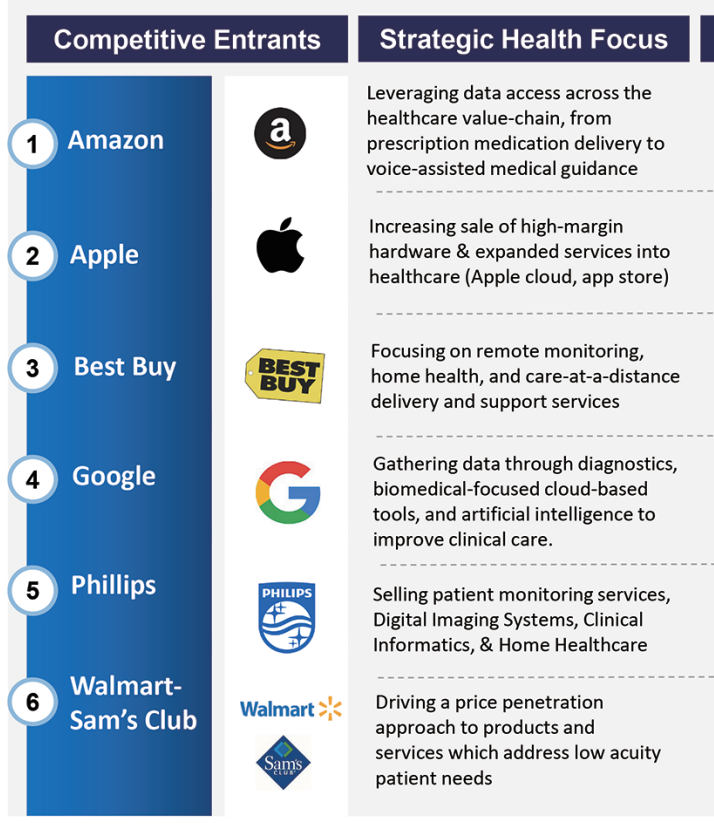

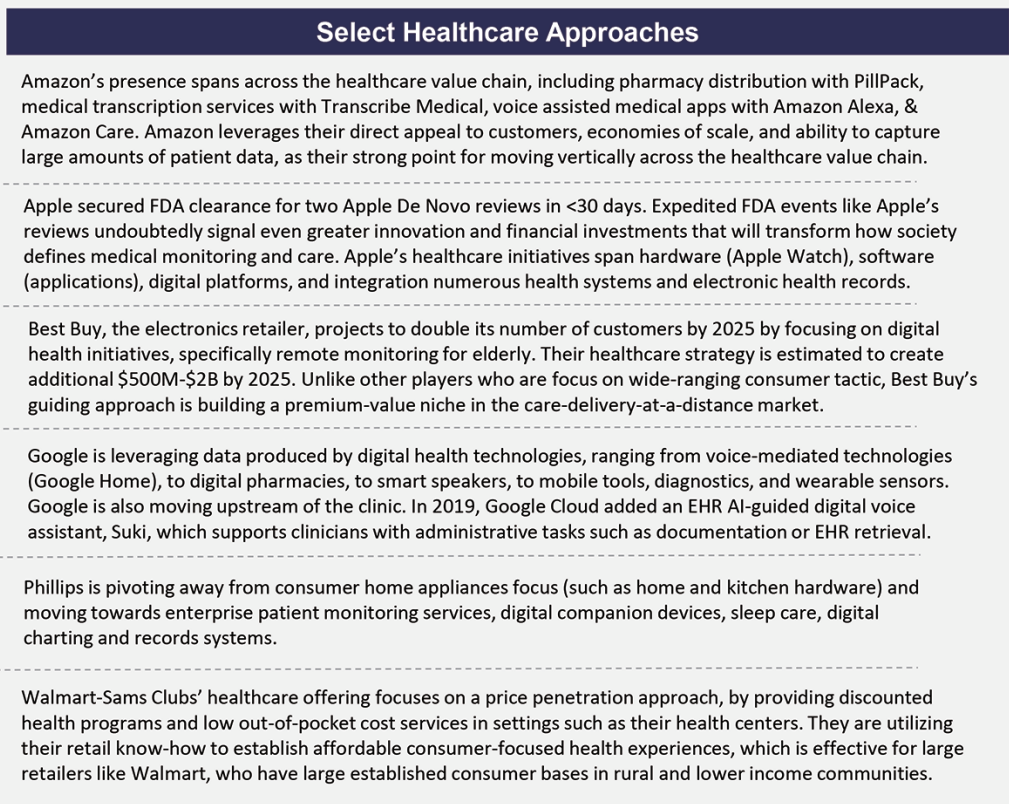

Figure 2 New Healthcare Business Models. This table above features select non-traditional cross-industry players (such as Amazon, Apple, Best Buy, Google, Phillips, and Walmart-Sam Club) and their wide-ranging strategic healthcare approaches.

\section{A new pace of innovation focused on cost transformation}

Advances in technology, such as AI, machine learning, and digital applications, can create cost efficiencies and reduce the current debilitating costs of healthcare. Examples of cost saving opportunities listed below include but are not limited to: digital applications/cross-channel engagement, utilization of demand aggregation platforms, enhanced economies of scale through negotiation power, and earlier detection.

\section{Harnessing healthcare costs through digital applications}

Digital capabilities are table stakes as more brick-and-mortar businesses shift to digital channels. Utilizing technology to ensure customer experience, while also finding opportunities to harness lost healthcare costs is key to creating sustained value. Avoidable costs in US healthcare exceed \$528B per year, and is growing (19). This is $2 \mathrm{x}$ the cost of global warming per year (\$224B) and comparable to the GDP in many of the top 30 ranking countries of the world [Thailand, Sweden, and Belgium's GDP (\$529B, \$528B, $\$ 517$, respectively)] (20). Fortunately, the rise of a new generation of robotic, precision, and virtual applications in the marketplace has and will continue to create boundless opportunities for enhanced operational efficiencies, financial transparency, and cost reduction. Technology giants and retailers are able to take advantage of these opportunities more quickly than other healthcare incumbents, due to their ability to innovate quickly, scale, and provide engagement through many channels (apps, email, texts, etc.). Healthcare players must establish and enhance consumer technology channels by anticipating emerging technology, capturing consumer-specific insights into actionable business priorities, and drive digital priorities to create long-term patientcentered product vision.

\section{Demand aggregation platforms}

Demand aggregation platforms are unique business models that have historically disrupted travel, media, retail, and several other industries, and is emerging in the healthcare sector as well. In a demand aggregation model, the more organizations that join forces and combine employees on a single platform, the more price competitiveness, financial leverage, and transparency is created. Some 
historic employer alliances like Haven (Amazon, JPMorgan, Berkshire Hathaway) had lofty goals to disrupt U.S. health care but unfortunately were not successful (21). The Covid-19 pandemic has challenged many organizations, and has highlighted the federal government's increasingly important role in aligning healthcare market incentives. Nonetheless, employee sponsored healthcare programs and large employer partnerships can bring together resources and capabilities that have the potential to enhance patientcentered experience, drive patient outcomes, and lower costs. While healthcare players cannot control all employer decisions, enhanced patient satisfaction and loyalty can make it easier for employees to choose historic health systems rather than switching to something new.

\section{Early detection, Automation, \& Virtual Care}

Technology and consumer product companies are creating drug delivery devices, wearables, implantable and digestible technologies, and methods for detecting vital signs that detect disease much earlier in the healthcare pathway. These technologies not only decrease healthcare costs, but are also supported by advanced analytics which fuel a cycle of continuous patient improvement. A shift in technology strategy will transform consumer engagement from an environment of static content, to an environment of personalized and targeted services. Release of content is no longer synchronized in cycles, but rather transforms to feature continuous and real-time consumer targeting. Healthcare knowledge in all settings of the healthcare ecosystem (primary care, specialty care, post-acute care, preventative care) shifts from primarily physical attendance to influential, virtual, and real-time exchanges. Machine learning, predictive algorithms, and other patternrecognition technologies will also reduce mis-diagnosis and errors in fields such as ophthalmology, radiology, cardiology, and oncology. Automation and AI-powered technologies can create workflow efficiencies, enhance medication adherence, reduce hospital admissions and re-admissions, and eliminate the surplus of unnecessary jobs. Adapting to the data era not only allows businesses to meet the changing demands of consumers, but also ensures greater access to care, enables cost reduction, improves quality of care, and is an imperative for enhanced survival.

\section{Healthcare as a service industry}

Historically, healthcare has been structured as a service to support providers and their staff, not consumers. By creating patient-centered business models, current players can enhance the traditional healthcare model by creating price transparency, establishing multi-modal communication channels, developing enhanced experience, and sharpening consumer's desire for more through e-commerce-like choice.

Service oriented care is possible through in-person healthcare delivery reform, and new models such as careat-a-distance. Inside the clinic, non-traditional players are already forcing traditional healthcare players to respond in a number of ways. Various health organizations, such as Inspira Health Network, are following Apple's Genius Barstyle environment by creating health technology support stations at the entrance of their facilities to better support patients (22).

Patient-centered healthcare services are wide-ranging, but healthcare channels and technologies such as Alexa pharmacy services are just the beginning for at-home advances. Voice-mediated technologies are more apt to evolve into virtually-assisted avatars, 3D holograms, and personalized at-home medical coaches. By seamlessly collecting, synthesizing, updating, and integrating patientspecific data with biomedical knowledge, virtual applications have the potential to create bespoke treatment plans and guide core elements of a patient's pharmacy, clinical, or self-care journey. These care offerings have a wide-range of personalized applications, starting with self-care (mental health, exercise, diet, physical therapy) through specialtycare (remote monitoring for diabetes, high blood pressure, etc.) and a wide-range of other services across the healthcare continuum.

\section{Conclusions}

As the pace of transformation in healthcare increases, healthcare incumbents who have for generations commanded large revenue pools in single industry sectors, will now battle new non-traditional competitive entrants. Consumer expectations are shifting, and competition will continue to get more intense as services are offered directly to consumers. The four imperatives listed above: (I) moving from brickand-mortal to connected and mobile health services; (II) engaging cross-sector collaboration and consolidation; (III) driving innovation for cost transformation; (IV) understanding healthcare as a service industry - are necessary for long term business sustainability. Healthcare players need to rapidly adopt digital technology, develop strategies 
to develop patient loyalty, create cross-industry capabilities, or risk falling behind. Winners will create patient-centered experiences through digital innovation, which will drive patient loyalty and the next generation of growth.

\section{Acknowledgments}

Funding: None.

\section{Footnote}

Provenance and Peer Review: This article was a standard submission to the journal. The article has undergone external peer review.

Peer Review File: Available at http://dx.doi.org/10.21037/ht20-26

Conflicts of Interest: The author has completed the ICMJE uniform disclosure form (available at http://dx.doi. org/10.21037/ht-20-26). The author has no conflicts of interest to declare.

Ethical Statement: The author is accountable for all aspects of the work in ensuring that questions related to the accuracy or integrity of any part of the work are appropriately investigated and resolved.

Open Access Statement: This is an Open Access article distributed in accordance with the Creative Commons Attribution-NonCommercial-NoDerivs 4.0 International License (CC BY-NC-ND 4.0), which permits the noncommercial replication and distribution of the article with the strict proviso that no changes or edits are made and the original work is properly cited (including links to both the formal publication through the relevant DOI and the license). See: https://creativecommons.org/licenses/by-nc-nd/4.0/.

\section{References}

1. Donvan J, Intelligence Squared Debates. Retail Alliances Not Washington - Will Save the U.S. Healthcare System [Internet]. Vol. Mayo Clini. Available online: https://www. intelligencesquaredus.org/debates/retail-alliances---notwashington---will-save-us-health-care-system

2. Kalra S, Baruah MP, Unnikrishnan AG. Responsible Patient-centered Care. Indian J Endocrinol Metab 2017;21:365-6.
3. Landi H. Kaiser Permanente, Molina Healthcare, Humana take top spots for digital experience. FierceHealthcare [Internet]. Technology (Questex LLC.). Available online: https://www.fiercehealthcare.com/payer/kaiserpermanente-molina-healthcare-and-humana-take-topspots-for-digital-experience

4. Kaiser Permanente. Kaiser Permanente again tops annual consumer loyalty study. NICE Satmetrix 2018 US Consum NPS® Benchmarks [Internet]. Kaiser Per. Available online: https://about.kaiserpermanente.org/ourstory/news/accolades-and-awards/kaiser-permanenteagain-tops-annual-consumer-loyalty-study

5. RetentlyNPS. What Do Companies with High Net Promoter Score Have in Common? Mark Leaders' Net Promot Score. Fred Reich.

6. RetentlyNPS. The Reasons Behind Apple's Customer Loyalty and High NPS. Net Promot Score [Internet]. Fred Reich. Available online: https://www.retently.com/ blog/apple-nps/

7. Customer Guru. Cigna Corporation Net Promoter Score \& 2020 Benchmarks. Cust Guru NPS Track Segmented Cust Satisf [Internet]. 2020;Net Promot. Available online: https://customer.guru/net-promoter-score/cignacorporation

8. RetentlyNPS. What is a Good Net Promoter Score? (2020 NPS Benchmark). Net Promot Score [Internet]. Fred Reich. Available online: https://www.retently.com/blog/ good-net-promoter-score/

9. Burdakin A. Best Buy's Healthcare Strategy: 5 Million Seniors in 5 Years. Motley Fool, LLC [Internet]. Market dat. Available online: https://www.fool.com/ investing/2019/10/01/best-buys-healthcare-strategy-5million-seniors-in.aspx

10. Reichheld F, Bain \& Company Inc. Prescription for cutting costs: Loyal relationships. Bain Company, Inc Online [Internet]. (Harvard Business School Publishing). Available online: https://media.bain.com/Images/BB_ Prescription_cutting_costs.pdf

11. Gwin K. How to use NPS in healthcare: A primer from MU Health Care's CXO. NRC Heal Hum Underst J [nternet]. Available online: https://nrchealth.com/how-to-use-nps-inhealthcare-a-primer-from-mu-health-cares-cxo/

12. Wicklund E. Walgreens Shutters Retail Health Clinics, Eyes Telehealth Partnerships. mHealth Intell [Internet]. (Xtelligent Healthcare Media, LLC). Available online: https://mhealthintelligence.com/news/amp/walgreensshutters-retail-health-clinics-eyes-telehealth-partnerships

13. Wicklund E. Walgreens, Microsoft Announce mHealth, 
Telehealth Partnership. mHealth Intell [Internet]. (Xtelligent Healthcare Media, LLC.). Available online: https://mhealthintelligence.com/news/walgreensmicrosoft-announce-mhealth-telehealth-partnership

14. Startribune B. Best Buy sees customers' homes as its next frontier. Startribune Bus Column [Internet]. 2019; Available online: http://m.startribune.com//best-buysees-more-growth-ahead-in-next-5-years-and-more-costcuts/561318352/

15. Arndt R. Apple scores FDA clearance for heart rhythmsensing Apple Watch. Mod Healthc [Internet]. Technology. Available online: https://www.modernhealthcare. com/article/20180912/NEWS/180919963/applescores-fda-clearance-for-heart-rhythm-sensing-applewatch\#: :text=Apple scores FDA clearance for heart rhythmsensing Apple Watch,-Rachel Z.\&text=Apple has rece

16. Comstock J. Apple's ECG announcement was likely years in the making, but its timing was remarkable. Mobi Heal News [Internet]. Healthcare. Available online: https://www.mobihealthnews.com/content/apples-ecgannouncement-was-likely-years-making-its-timing-wasremarkable

17. Drees J. Google Cloud adds EHR voice assistant: 4 things to know. Beckers Heal IT [Internet]. Beckers Ho. Available online: https://www.beckershospitalreview.com/ ehrs/google-cloud-adds-ehr-voice-assistant-4-things-to-

doi: $10.21037 /$ ht $-20-26$

Cite this article as: Manetta A. The rapidly evolving role \& implications for cross-industry convergence in the U.S. healthcare system. Health Technol 2021;5:1. know.html

18. Hale C. Philips to drop its home appliances unit in healthcare pursuit, plus a new head of connected care. Fierce Biotech [Internet]. MedTech Ca. Available online: https://www.fiercebiotech.com/medtech/philips-to-dropits-home-appliances-unit-healthcare-pursuit-a-new-headconnected-care

19. GMTRx Institute. Medication-related morbidity and mortality costs exceeds \$528B. 2019;061719. Available online: https://gtmr.org/wp-content/uploads/2019/09/ Proof-Points-Infographic-6.17.19.pdf

20. Statistics Times. Projected GDP Ranking. Stat Online Econ Outlook [Internet]. (International Monetary Fund World Economic Outlook (October-2020)). Available online: http://statisticstimes.com/economy/projectedworld-gdp-ranking.php.

21. Farr C. Everything we know about Haven, the Amazon joint venture to revamp health care. CNBC LLC [Internet]. A Division (HealthTech Matters). Available online: https://www.cnbc.com/2019/03/13/what-is-havenamazon-jpmorgan-berkshire-revamp-health-care.html

22. Cohen J. Hospitals setting up tech bars for chronic disease care. Mod Healthc [Internet]. Crain Comm. Available online: https://www.modernhealthcare.com/patients/ hospitals-setting-up-tech-bars-chronic-disease-care 